(c) 2011 IEEE. Personal use of this material is permitted. Permission from IEEE must be obtained for all other uses, in any current or future media, including reprinting/republishing this material for advertising or promotional purposes, creating new collective works, for resale or redistribution to servers or lists, or reuse of any copyrighted component of this work in other works. 


\title{
Towards Supply Chain Excellence using Network Analysis
}

\author{
P. Alexander, H. Armstrong, I. McCulloh \\ School of Information Systems \\ Curtin University of Technology \\ Perth, Western Australia \\ \{p.alexander, h.armstrong\}@curtin.edu.au, cusum@gmail.com
}

\begin{abstract}
The literature suggests a growing interest in the application of network analysis in supply chain management. However this has been at the organizational rather than the process level. We believe there is value in applying such analysis to internal processes in supply chain networks. This study uses network analysis techniques to investigate the Stewart [8] framework for excellence in supply chains which considers the impact of delivery performance, flexibility and responsiveness, logistics cost and assets management. We analyze traditional process flow charts as a network in which nodes represent processes, and links between processes have values associated with dimensions of excellence. The supply chain is analyzed and viewed using measures of centrality and clustering related to the dimensions of excellence, and compared with traditional perceptions of the same processes which are more related to time criticality. Overall, the study indicates that traditional means of managing supply chains are not only unfocused in terms of excellence, but are compromised through inability to recognize the importance of various process groups, with a serious mismatch of resourcing as a result. The study provides early findings supporting the future development of a methodology to better manage supply chains using network analysis, in particular to better prioritize resources on critical processes.
\end{abstract}

Keywords- network analysis, internal supply chain, process groups, subgroups, network centrality

\section{INTRODUCTION}

The application of network analysis to supply chain management (SCM) has increased over the past two decades in particular, based on 'network thinking' and investigating the interaction of the actors, resources and chains of activities (see for example, Harland [1], Lazzarini et al. [2], Nagurney et al. [3], Nooteboom [4], Powell [5]). Much of the research so far focuses on the external supply chain, or the integrated process involving business entities such as suppliers, manufacturers, distributors and retailers, working together to acquire raw materials, convert these into products and deliver these products to retailers [6]. A supply chain network is a network of these independent business entities involved, through upstream and downstream links, in the different processes and activities that produce goods or services to customers [7]. An essential process group within the internal supply chain (SC) is the order fulfillment process encompassing receiving orders and raw materials through to delivery of the finished goods.
This set of processes can occur in either an internal or external SC, depending on how the chain is constructed, with the increasing outsourcing of the entire process or parts thereof.

This paper discusses the analysis of the internal supply chain (ISC) using network analysis based on the Stewart framework [8] for measuring supply chain excellence and compares the results with those using traditional methods. The paper opens with a discussion of current approaches to analyses of supply chains, and notes that there is little direct objective connection to "excellence" as it applies to supply chains. Also discussed is the role network analysis has the potential to play in providing a more informed and holistic internal supply chain analysis approach. Data is gathered from extensive ISC process mapping in a single manufacturing organization and associated questionnaires are used to determine the basis for links affecting excellence and other relevant features between the processes. Network analysis is used to process this data, and measures compared to assess the difference in perceptions of importance of the supply chain processes when considered using a traditional approach which emphases criticality of processes based on the speed with which their absence will negatively impact the ISC as a whole. Additional data is used to compare these other measures with actual and planned expenditure on (improving) processes, which provides insight into the company's actual prioritization of process within its ISC.

\section{APPROACHES TO SUPPLY CHAIN ANALYSIS AND MANAGEMENT}

Most physical and information activities in a business focus on interaction either directly or indirectly to manage SCs. Thus Enterprise Relationship Resource Planning (ERP) systems, which work at an enterprise level, have many functional modules to manage aspects of SCs. For example SAP, the world's most dominant ERP has 50 standard modules. Of these, 23 are predominantly related to supply chain management and aspects of supply while only 17 have little involvement in SCM [9]. It is not surprising therefore that SC performance is a critical focus for almost all organizations.

To provide direction in SCM, it is first necessary to define the desired outcomes and the key performance indicators (KPIs) that relate to those outcomes. As SCs are a complex amalgamation of almost all the organization's processes, and 
increasingly those of its partners and customers, this is not an easy formula to derive [10]. For instance, performance of a warehouse will influence many other parts of the ISC, and so its optimal performance may need to be traded to provide better overall outcomes [7]. To address this, some approaches take a multi-parameter approach which looks at many measures throughout the ISC and compares them to best practice in particular parts of the supply chain, or to overall best practice by means of benchmarking. The frameworks of Gunasekaran [11] and the well accepted Supply Chain Council Operations Reference (SCOR) model adopt this approach [12]. Other approaches involve a higher view. Melnyk and colleagues [13] argue that SCs should be customer focused, based on six customer focused outcomes; innovation, cost, resilience, security, responsiveness and sustainability. Many others take a more pragmatic and operational view, considering that SCs should be managed with a close link to the bottom line, however doubt has been raised on the ability to define the variables for supply chain metrics to determine profitability [14]. This aligns with the very common practice of justifying expenditure (in this case on improving SC performance) with measures of return on investment.

Stewart [8] aligns the SC outputs to measures of 'excellence' which have more than a passing similarity to those customer focused outcomes of Melnyk et al. [13] arguing supply chains need to optimally deliver four dimensions of outputs to enable them to outperform other competitors. Stewart described these as dimensions of excellence. In his model 'delivery performance' drives customer satisfaction; 'flexibility and responsiveness' allows the SC to work effectively when dealing with changes in demand or specific compromises; 'logistics cost' uses SCM to configure the SC to deliver low in order management, material acquisition, inventory carrying costs and SC finance costs; and 'asset management' efficiently utilizes its assets (warehouses, machinery, people).

Many approaches to measuring SC effectiveness attempt to make many measurements of KPIs across the supply chain outputs and processes. Such measures may be internal to the organization and somewhat ad hoc, or more formalized; for instance the SCOR framework [12]. These measures can certainly assist in allowing companies to reach specific SC performance targets, assess progress from a previous state and potentially serve as benchmarks against best practice their particular industry. However they do not directly link performance with high level business goals, or readily determine many of the optimization trade-offs of specific parts of the SC that must be made to ensure optimization of the SC as a whole.

SCs are defined in part as sets of sequential, vertically organized transactions representing successive stages of value creation and are dependent for efficient operation on appropriate resource allocation and information flow [11]. In practice this operation is enabled through well defined processes operating pervasively across the ISC. Such processes work as interconnected groups ('Process Groups') and have a unifying goal across the whole organization. They are influenced by, and themselves influence organizational structures, KPIs and policies, structure and functional goals of an enterprise. Process Groups (PGs) are interlinked, but these linkages are generally confined to discrete activities, tasks, flags that pass physical materials, information, or status and therefore effect coordination of all such groups in the enterprise, and now frequently through intercompany IT communication, between enterprises.

While effective tools are available to design ISC processes, creating and running operationally efficient processes is less well defined, and in many organizations this is by trial and error. Breakdowns in efficiencies can be expressed in terms of lag times, delays, and over- or under-resourcing. It is no coincidence that these are also project management terms and it is therefore not surprising that project management tools such as Gantt charts, PERT and Critical Path analyses can be applied to processes. Of course, these tools are optimized for projects where a "process" consists of the tasks and interactions run (once) to complete a project. Processes that make up ISCs however, are cyclic in nature and so there are limitations to the applications of project management concepts and tools.

\section{NETWORKS AND SUPPLY CHAINS}

Technologies have now become so integrated into processes, and have so modified them that designing, operating and mapping them at an inter-organizational level, has lead to the use of 'Chain and Network Science' (CNS). In CNS a "network" is made of "actors", "resources" and "activities" [16]. This focus makes CNS a valuable way of looking at many SCM problems since modern SCM benefits from sophisticated collaborations. CNS has given rise to a view of interorganizational SC networks as 'Netchains', defined as "sets of networks comprised of horizontal ties between firms within a particular industry or group, sequentially arranged based on vertical ties between firms in different layers" [2]. Activity in Netchains is concentrated on the interactions between the actors in the supply chain. Netchain analysis focuses, like CNS, on inter-organizational links. In both analyses network science has so far focused on interconnections and not into the individual processes inside an organization, the so-called internal supply chain.

A different approach is offered by Easley and Kleinberg [17] based upon analysis of network paths, in contrast to analysis of nodes, where measures of flow can be determined. A network path approach is also used by Borgatti [18], who states that conceptually systematical analysis of relationships between nodes in a set consequently produces chain or paths that vary in length and may indirectly connect all nodes with all others. These paths provide access ways for nodes to influence each other. The focus of Borgatti's discussion, however, concentrates on ego-networks and the application of social network analysis to networks of people and how they interact and pass information.

Lewis studied the vulnerability of critical infrastructures using network analysis in energy production supply chains [19] however his research was limited to risk analysis and security concerns. Although some analysis has been undertaken on transportation, delivery and distribution network, this body of work is small [20] and little has been published on the application of network science to supply chains. 


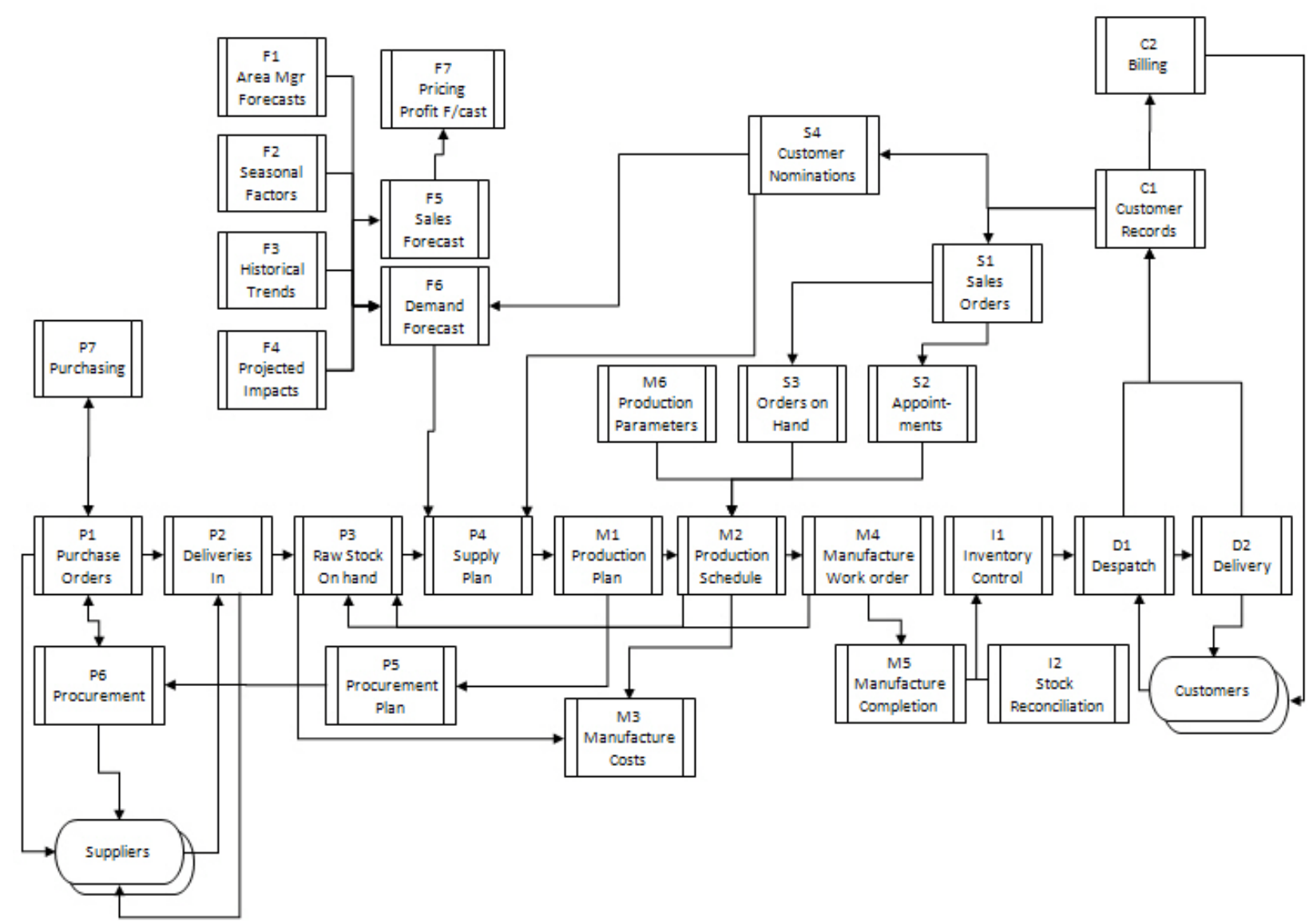

Figure 1. ChemCoy Ltd. Supply chain process groups

\section{RESEARCH METHODOLOGY}

The target organization, anonymized and referred to as ChemCoy Ltd, is a dominant regional process manufacturing company producing chemical for use in food production. ChemCoy's internal supply chain includes demand forecasting, procurement, production, sales, inventory, despatch and customer management. The processes used in its ISC (that is, not including external suppliers) were examined as part of a 24 month process improvement project that also had the objective of implementing a new enterprise information system. Indepth analysis of the processes and their links to each other was conducted and modeled (see Figure 1).

The actual nature of the processes was determined through analysis of the existing ERP used across the organization, spreadsheet and informal reports, and interviews with key users and staff by means of focus groups. High level functional Process Groups (PGs) were determined, each PG consisted of many individual processes, though only the net outputs and inputs at PG level were considered in this study (see Figure 1 and Table I). These PGs corresponded to well-defined business functions aligned to the ERP modules and organizational structures; namely sales forecasting (processes F1-F7), procurement (P1-P7), sales (S1-S4), production/manufacturing
(M1-M7), inventory (I1-I2), dispatch (D1-D2) and customer management (C1-C2).

TABLE I. Process Groups ANALyZed For ChemCoy LTD.

\begin{tabular}{|l|l|l|l|}
\hline PG ID & Description & PG ID & Description \\
\hline P1 & Purchase Orders & D1 & Despatch \\
\hline P2 & Deliveries In & D2 & Delivery \\
\hline P3 & Raw Stock on Hand & C1 & Customer Records \\
\hline P4 & Supply Plan & C2 & Customer Billing \\
\hline P5 & Procurement Plan & S1 & Sales Orders \\
\hline P6 & Procurement & S2 & Appointments \\
\hline P7 & Purchasing & S3 & Orders on Hand \\
\hline M1 & Production Plan & S4 & Customer Nominations \\
\hline M2 & Production Schedule & F1 & Area Manager Forecasts \\
\hline M3 & Manufacture Costs & F2 & Seasonal Factors \\
\hline M4 & $\begin{array}{l}\text { Manufacture Work } \\
\text { Order }\end{array}$ & F3 & Historical Factors \\
\hline M5 & $\begin{array}{l}\text { Manufacture } \\
\text { Completion }\end{array}$ & F4 & Projected Impacts \\
\hline M6 & $\begin{array}{l}\text { Production } \\
\text { Parameters }\end{array}$ & F5 & Sales Forecast \\
\hline I1 & Inventory Control & F6 & Demand Forecast \\
\hline I2 & Stock Reconciliation & F7 & Pricing Profit Forecast \\
\hline
\end{tabular}

Key members involved in the project were asked to assess how long specific PGs could cease to function before 
significantly impairing overall supply chain performance, defined as "disruption to external inputs (suppliers) and outputs (customers). This is termed in this study, "Time Criticality" (Table II) and was selected to represent outcomes of typical critical path approaches to SCM, emphasizing predecessor/ successor relationships and associated ISC blockages. Network analysis of these processes was undertaken treating the time criticality as a single-dimension directed, valued network.

TABLE II. SCALE FOR MEASURING TIME CRITICALITY

\begin{tabular}{|l|l|}
\hline Rating & $\begin{array}{l}\text { Time before the process } \\
\text { would cause ISC failure }\end{array}$ \\
\hline 0 & No connection \\
\hline 1 & Weeks \\
\hline 2 & Days \\
\hline 3 & Hours \\
\hline 4 & Close to real-time \\
\hline
\end{tabular}

Key members involved in the project were then asked to assess how each of the four Stewart excellence framework measures related to each PG's relationship to the overall ISC. A scale of 0 (no relevance) to 4 (critical) was used. Network analysis of each of these responses was undertaken using ORA software. The PGs were entered as single class nodes. Analysis was undertaken with each of the four excellence measures as dimensions of a directed, valued meta-network. The findings of the excellence measures were then compared with those for the traditional approach using time criticality as the predominant measure.

\section{DATA ANALYSIS}

\section{A. Analysis Using Traditional Methods}

Both dollars expended and time criticality are important considerations in traditional SCM decision-making. To establish the actual level of financial allocation on PGs taken by ChemCoy Ltd, the expenditure on each PG was investigated over the previous 3 years and anticipated expenses for the next 2 years. Where expenditure was spread across several PGs, this was apportioned equally. This resulted in a ranking of PGs based on level of expenditure. Table III shows ranking of the top six expenditure areas on PGs.

Interviews indicated this priority was driven by perceptions of the potential for failure of a particular PG and its possible impact on the overall outputs of the company (not just ISC outputs), perception of the PGs' contributions to performance of the company, or lobbying by key staff. All expenditure was subject to a formal cost benefit analysis procedure which emphasized a $20 \%$ hurdle rate on return on investment (ROI).

TABLE III. FIVE YEAR EXPENDITURE ON PROCESS GROUPS RANKED IN ORDER OF AMOUNT FOR CHEMCOY

\begin{tabular}{|l|l|}
\hline Rank & Process Group \\
\hline 1 & C1 Customer Records \\
\hline 2 & S1 Sales Orders \\
\hline 3 & F5 Sales Forecasts \\
\hline 4 & D1 Despatch \\
\hline 5 & F1 Area Manager Forecasts \\
\hline 6 & M2 Production Schedule \\
\hline
\end{tabular}

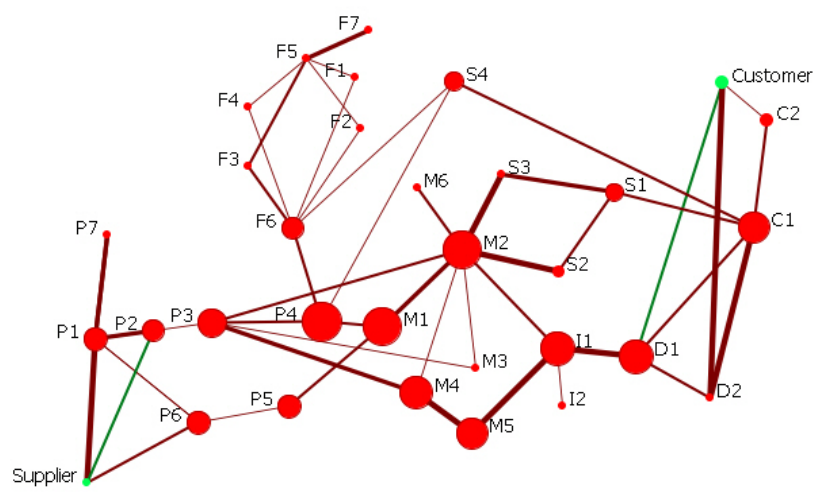

Figure 2. Network of process groups for ChemCoy Ltd. showing betweenness and weight of relationships for time criticality

Some expenditure was undertaken based on nondiscretionary justifications such as the need to match expansion of a PG to meet other business demands, addressing obsolescent equipment or systems, and changes to deal with organizational changes.

Measurement of 'time criticality' of PGs was selected to represent outcomes typical of the critical path approach to SCM, which emphasizes predecessor/successor relationships and ISC blockages. Key members involved in the project were asked to assess how long specific PGs could cease to function before significantly impairing overall ISC performance, which was defined to mean "disruption to external inputs (suppliers) and outputs (customers)”. Respondents rated PGs as 0 (no connection to ISC disruption), 1 (weeks before disruption), 2 (days before disruption), 3 (hours without disruption) and 4 (minutes or less before disruption). ChemCoy assigned values to time criticality across its PGs as illustrated in Figure 2. The weights or values for time criticality are reflected in the thickness of the links and the size of the nodes reflects the Betweenness centrality for each node.

Betweenness and degree centrality measures for the top six PGs for the time critical network can be seen in Table IV. High betweenness highlights the PG's relative importance in binding the network as a whole. At ChemCoy production PGs (M2, P4, M1, M4 and M5) are central, as is finished goods inventory management (I1), suggesting a very productionfocused ISC. The total degree centrality indicates the PGs that are well linked to numerous others. It also shows the importance of the Manufacturing part of the ISC, although now PGs closer to customers (C1 and D1) are also important. Underperformance or removal of these key PGs has the potential to fragment the network resulting in breaking down of the ISC.

TABLE IV. CENTRALITY MEASURES FOR THE TIME CRITICALITY NETWORK

\begin{tabular}{|l|l|l|}
\hline Rank & Betweenness & Degree \\
\hline 1 & M2 & M2 \\
\hline 2 & P4 & P1 \\
\hline 3 & M1 & I1 \\
\hline 4 & I1 & C1 \\
\hline
\end{tabular}




\begin{tabular}{|l|l|l|}
5 & M4 & D1 \\
\hline 6 & M5 & P3 \\
\hline
\end{tabular}

TABLE V. NEWMAN SUBGROUPS FOR TIME CRITICALITY

\begin{tabular}{|l|l|l|l|l|l|}
\hline Group & Size & Cluster Name & Members & $\begin{array}{l}\text { Internal } \\
\text { Links }\end{array}$ & $\begin{array}{l}\text { Silo } \\
\text { Index }\end{array}$ \\
\hline 1 & 2 & $\begin{array}{l}\text { External } \\
\text { stakeholders }\end{array}$ & $\begin{array}{l}\text { Customer, } \\
\text { Supplier }\end{array}$ & $0 \%$ & -1 \\
\hline 2 & 7 & Purchasing & $\begin{array}{l}\text { P1,P2,P3,P4, } \\
\text { P5,P6,P7 }\end{array}$ & $45 \%$ & -0.1 \\
\hline 3 & 6 & $\begin{array}{l}\text { Manuactur- } \\
\text { ing }\end{array}$ & $\begin{array}{l}\text { M1,M2,M3, } \\
\text { M4,M5,M6 }\end{array}$ & $35.7 \%$ & -0.28 \\
\hline 4 & 2 & Inventory & I1,I2 & $20 \%$ & -0.6 \\
\hline 5 & 2 & Despatch & D1,D2 & $14.3 \%$ & -0.71 \\
\hline 6 & 4 & Sales & S1,S2,S3,S4 & $25 \%$ & -0.5 \\
\hline 7 & 7 & Forecasting & $\begin{array}{l}\text { F1,F2,F3,F4, } \\
\text { F5,F6,F7 }\end{array}$ & $81.8 \%$ & 0.63 \\
\hline 8 & 2 & Customer & C1,C2 & $16.7 \%$ & -0.67 \\
\hline
\end{tabular}

An analysis of subgroups using the Newman algorithm results in eight groups (see Table V). These groups are recognizable conventional ISC clusters and have been provided with representative names. The silo index is also shown (silo index ranges from -1.0, indicating all links are to external PGs, to 1.0, indicating all links are to internal PGs). High siloing is indicated only in the Forecasting cluster, which might therefore be expected to be much less responsive to outside influences than to internal ones. The other PGs have a generally external focus, particularly the Despatch and Customer clusters.

\section{Insert discussion on resources and tasks for time criticality}

\section{B. Analysis Using Excellence Dimensions}

Stewart's [8] dimensions of excellence were analyzed in a similar way to the time criticality analyses. While these excellence dimensions are not the only possible approach, they represent a rational means to serve as a basis for informed SCM decision-making at a holistic level. Separate networks were developed for asset management, logistics cost, delivery and flexibility. The four networks are illustrated in Figures 3-6, with nodes sized by betweenness and link width denotes the relationship weights. Links to nodes that are isolates are valued at zero and are therefore not important in achieving that factor of excellence. The network representing excellence via asset management (Figure 3) indicates that the purchasing and manufacturing process groups are the most important to this dimension. Sales, sales forecasting, production parameters and customer-related process groups carry little weight in considerations of asset management.

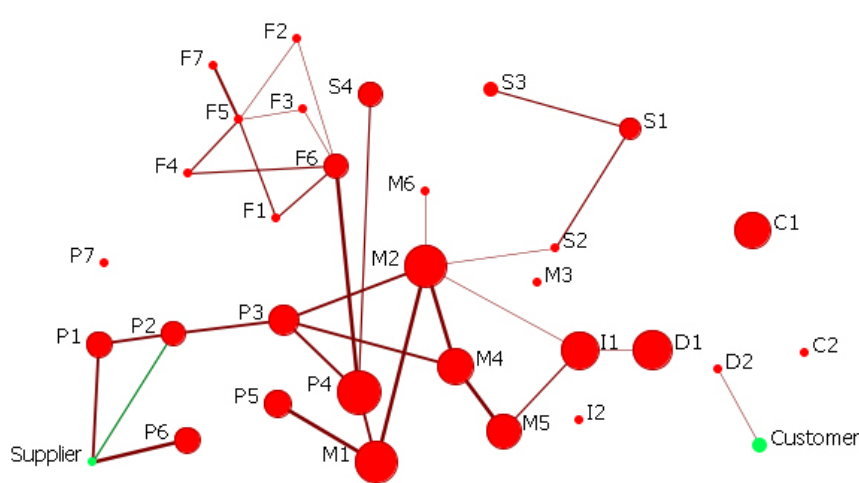

Figure 3. Network for Asset Management Dimension

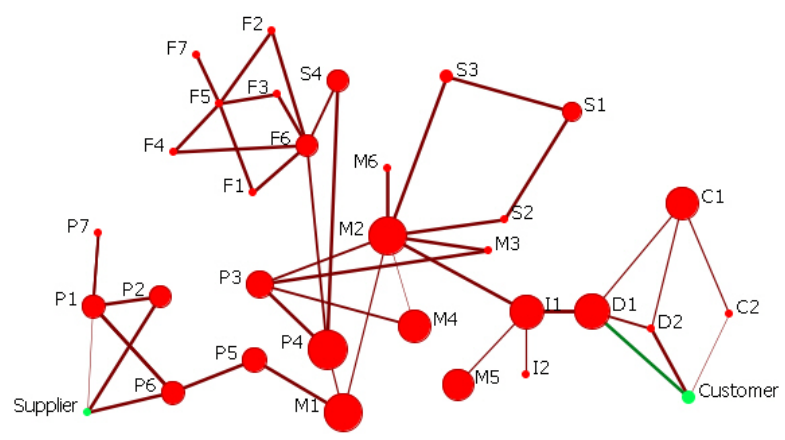

Figure 4. Network for Logistics Cost Dimension

The dimension of logistics costs (Figure 4) indicates high weightings in process group links in the purchasing, manufacturing, sales and sales forecasting as would be expected, as these process groups relate directly to profitability considerations. The delivery performance network (Figure 5) shows the emphasis on the latter stages of the ISC particularly the manufacturing and despatch process groups. Customer, sales, sales forecasting and purchasing carry little importance in this the delivery performance dimension of excellence.

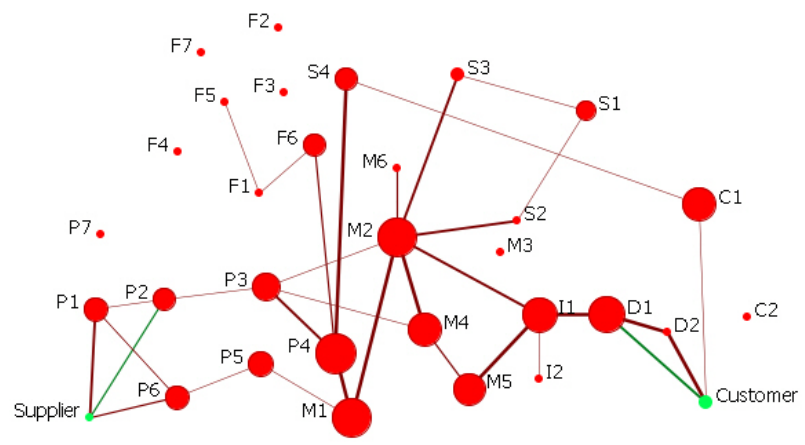

Figure 5. Network for Delivery Performance 


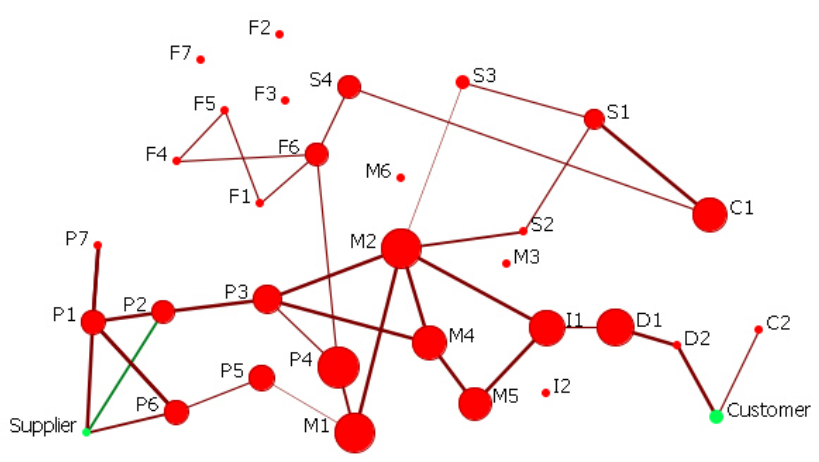

Figure 6. Network for Flexibility

Flexibility also has little emphasis on customer, sales and particularly sales forecasting (Figure 6). Also noted is the absence of links to M3 (manufacture costs), M6 (manufacture parameters) and I2 (stock reconciliation) which are isolates. The emphases in the flexibility dimension network are the purchasing and manufacturing process groups, the early stages of the ISC.

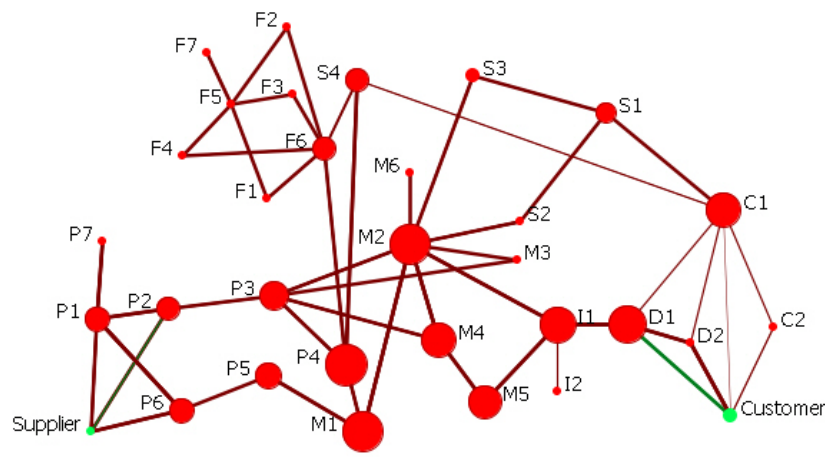

Figure 7. Combined Excellence Dimensions Network

The network combining all four excellence factors is displayed in Figure 7. The purchasing and manufacturing process groups carry the highest weights, indicating that this particular organization views excellence as being linked to the upstream internal supply chain activities.

Measures of betweenness centrality for the PGs can be seen in Table VI and total degree centrality in Table VII. These tables rank the highest six PGs. It can be seen that the betweenness measure for each of the four dimensions of excellence produces different results, with the combined result for the total four factors strongly reflecting those of the asset management dimension.

The PGs high in betweenness are potentially influential as they are gatekeepers between the other PGs, filtering information, products, supplies, plans and the like. These PGs are of interest due to their power to filter, control and pass flows from one PG to another. In ChemCoy, Manufacturing PGs are prominent in this way, although Sales Nominations (S4) is notably important.

TABLE VI. BETWEENNESS FOR PGS FOR THE FOUR DIMENSIONS OF EXCELLENCE.

\begin{tabular}{|c|c|c|c|c|c|}
\hline Rank & $\begin{array}{c}\text { Asset } \\
\text { Mgt }\end{array}$ & Cost & Delivery & Flexibility & All 4 \\
\hline 1 & M2 & S4 & S4 & S4 & M2 \\
\hline 2 & S4 & M1 & M2 & M1 & S4 \\
\hline 3 & M1 & M2 & M1 & M2 & M1 \\
\hline 4 & M4 & S3 & S3 & S3 & I1 \\
\hline 5 & S3 & P1 & I1 & M4 & D1 \\
\hline 6 & F6 & F6 & M4 & S1 & M4 \\
\hline
\end{tabular}

TABLE VII. TOTAL DEGREE FOR PGS FOR THE FOUR DIMENSIONS OF EXCELLENCE.

\begin{tabular}{|l|l|l|l|l|l|}
\hline Rank & $\begin{array}{l}\text { Asset } \\
\text { Mgt }\end{array}$ & Cost & Delivery & Flexibility & All 4 \\
\hline 1 & M2 & M2 & M2 & S1 & M2 \\
\hline 2 & S3 & F6 & S4 & M2 & S1 \\
\hline 3 & S4 & F5 & I1 & S3 & F6 \\
\hline 4 & M1 & S1 & M1 & M4 & C1 \\
\hline 5 & M4 & I1 & D1 & I1 & S2 \\
\hline 6 & F6 & S3 & M4 & P2 & S3 \\
\hline
\end{tabular}

TABLE VIII. BOUNDARY SPANNERS FOR THE FOUR DIMENSIONS OF EXCELLENCE

\begin{tabular}{|l|l|l|l|l|}
\hline Rank & Flexibility & Delivery & Cost & Asset Mgt \\
\hline 1 & S4 & P1 & M1 & S4 \\
\hline 2 & P1 & P2 & S4 & M1 \\
\hline 3 & M1 & S3 & P1 & M2 \\
\hline 4 & S3 & S2 & S3 & I1 \\
\hline 5 & M2 & M1 & M2 & M5 \\
\hline 6 & SA3 & S1 & P2 & M4 \\
\hline
\end{tabular}

TABLE IX. CRITICAL SET OF NODES WHOSE REMOVAL MOST FRAGMENT OR DISRUPTS THE NETWORK.

\begin{tabular}{|l|l|l|l|l|}
\hline Rank & Flexibility & Delivery & Cost & Asset Mgt \\
\hline 1 & M2 & S3 & S4 & S4 \\
\hline 2 & M5 & S4 & M2 & M2 \\
\hline 3 & F6 & M2 & D1 & M4 \\
\hline
\end{tabular}

Boundary spanners bridge connections to other clusters by having concurrent membership in overlapping PG groups. Boundary spanners are high in betweenness but lower in degree, positioning them as key connectors between groups. These PGs may indicate choke points in the network and are areas that, depending on process times, could need prioritization. These are shown in Table VIII, indicating that sales (S4) and manufacturing (M1, M2) PGs are important in this respect.

Table IX illustrates how the overall ISC performs under the stress of progressively removing PGs, and indicates that except in flexibility where manufacturing (M2, M5) PGs are key, sales (S3, S4) are also critical. Sales forecasting (F6) and despatch (D1) PGs are also key in particular dimensions.

An analysis of subgroups using the Newman algorithm was performed for the combined effect of all four dimensions of excellence. This resulted in five clusters (Table X) which, 
unlike those determined using time criticality, are not recognizably conventional. Silos are also heavily internally focused in this case, indicating that each cluster is very internally focused with few links to other PGs.

Although it is expected that sets of process groups relating to the same overall function would be nominated in the same subgroup, this is not reflected in Table $X$. While some subgroups are obvious and expected, such as the sales forecasting subgroup, others indicate that the strength in like PGs is not as strong as it could be.

TABLE X. NEWMAN EXCELLENCE SUBGROUPS

\begin{tabular}{|l|l|l|l|l|}
\hline Group & Size & Members & $\begin{array}{l}\text { Internal } \\
\text { Links }\end{array}$ & $\begin{array}{l}\text { Silo } \\
\text { Index }\end{array}$ \\
\hline 1 & 5 & P1,P2,P6,P7, Supplier & $83.3 \%$ & 0.67 \\
\hline 2 & 9 & $\begin{array}{l}\text { P3,P4,P5,M1,M2,M3, } \\
\text { M4, M6,S4 }\end{array}$ & $55 \%$ & 0.1 \\
\hline 3 & 7 & $\begin{array}{l}\text { M5,I1,I2,D1,D2,C2, } \\
\text { Customer }\end{array}$ & $57.2 \%$ & 0.143 \\
\hline 4 & 4 & S1,S2,S3,C1 & $30 \%$ & -0.4 \\
\hline 5 & 7 & F1,F2,F3,F4,F5,F6,F7 & $81.8 \%$ & 0.64 \\
\hline
\end{tabular}

Insert discussion the relevance of each grouping to the overall organisation's SC goals (irrelevance of the F processes group 5 with high internal links, specialization of the Ps in group 1 with high internal links, Ms being strongly linked with P3-P5 in group 2) etc.

Discuss the impact of this on decision making for resources and tasks for excellence measures.

\section{FINDINGS AND DisCUSSION}

\section{A. Traditional Supply Chain Analysis}

When looking at improving supply chain processes preexisting paradigms emphasize the time criticality of the contribution of each group to the functioning of the supply chain as a whole; that is, how long it takes for the overall supply chain to fail if the PG does not contribute its outputs. Such a paradigm prioritizes enterprise resources to those that appear to be more time critical, and is a common approach to maintaining ISC continuity. However, when compared to the actual outcomes used by ChemCoy for prioritizing resourcing for its ISC (Table I), there are major differences in priorities established with existing approaches compared to those established with network analysis of time criticality (Table $\mathrm{X} 12)$. It appears that many other factors including lobbying and subjective perception, and not just the time criticality, affect the decisions on resourcing PGs. So while time criticality analysis suggests that production scheduling (M2) is the most critical PG, this is not reflected in expenditure. Illustrating the converse sales orders (S1) is heavily resourced in Chemcoy though it is far less critical in its contribution to maintaining continuity of the ISC.

Of course, merely investing money into PGs is not an absolute indication of the performance of those PGs it is certainly an indication of the business's focus, and there are significant differences in the analyzed versus the ad hoc perspective that ChemCoy is taking.

\section{B. Supply Chain Excellence using Network Analysis}

As an alternative, the Stewart framework for measuring SC excellence provides a way to determine the contribution of process groups to a holistic perspective of ISC performance. It quantitatively prioritizes resource allocation at an overall level without the need to examine a myriad of parameters typical of approaches such as SCOR, which do not themselves maintain focus on a particular unifying outcome; in this study, excellence. This represents a clear alternative to the time criticality aSSESSments of PGs taken in ChemCoy' TABLE XIII. mainly ad-hoc way.

\section{Add discussion on impact of resources and tasks decisions.}

While a single process group ranks highest to achieve excellence in each measure, there are unique sets of PGs that must be focused on to optimize each measure. Also, while there is some consistency between prioritizations based on time criticality versus measures of excellence, the prioritizations do not match at the detailed level. That is, PGs which are key to achieving an excellent ISC are not the same as those most central to achieving the best time criticality. This is a significant finding suggesting that ChemCoy must choose what its ISC goals are and apply its resources to the appropriate PGs.

\section{New Internal Supply Chain Views}

The process map in Figure 1 provides an orthodox view of an ISC typical of those that are routinely developed for companies, and built almost entirely by establishing the source and destination PGs, rather than what the PGs and their links actually achieve in a unified way. This creates a representation of clusters of PGs that influence the management structure of the business and which influences how the ISC is managed.

We find that this orthodox view of the ISC, represented in ChemCoy's organizational structure and management approach is confirmed with Newman analysis of the time criticality dimension (Table IV). However, it is quite different to the structure suggested by same analysis of excellence parameters (Table VIII). This implies that the organization's SCM activities and structure is not aligned with natural ISC structures to deliver excellence. Having said this, it should be noted that the clusters related to excellence tend to high siloing which could create equally siloed functional structures in any organization which adopts this approach.

\section{CONCLUSIONS AND FUTURE RESEARCH}

This research suggests a more accurate, richer view of ISCs can be established with network analysis, one that focuses attention and resources more accurately and in a way that can deliver better outcomes in terms of excellence of overall SC performance.

ISC performance in manufacturing organizations is commonly managed by creating key performance indicators (KPIs). Ultimately these KPIs are established within the context of the organization and management structure. This leads to a complex matrix needed to monitor and manage the 
overall SC performance, and there is no evidence in our study of a wide scale conscious connection of these with running an "excellent" SC. Indeed, the definition of excellence is not clearly referenced in terms of KPIs, but at most implied, and then only for some.

The paper finds that to achieve "excellence" in running an ISC requires an understanding of key PGs in terms of their interaction across the whole ISC and not just their time criticality. Some PGs are more critical than others directly, as boundary spanners that link groups of processes, and more subtly as indirect brokers for other PGs. Comparison of these results with the company's actual commitment to making sure these PGs are running well shows many significant anomalies that indicate the company is not aligning its resources in a way that creates an excellent internal supply chain.

Newman groupings suggest that to focus on excellence, SCs should be represented in a different way than currently viewed. This may have far reaching implications for the suitability of current practices of SCM in focusing on excellence, and indeed on how SCM is presented and taught at tertiary level to practitioners.

Our work suggests network analysis is a valuable tool in setting agendas for managing and resourcing in ISCs, particularly in providing them with high level objectives such as excellence. An important adjunct to this is the ability to see a "big view" of ISC excellence and provide an excellenceoutcome focus for other supply chain management tools.

Based on network analysis we see ISCs more as "Networks of Process Groups”. While traditional approaches to SCM such as critical chain analysis, focus on constraints of resources, a Process Group Networks view extends this to focus on the relationships between PGs, to their richness, their contribution to the ISC as a whole, and to direct and indirect roles they may play in achieving high level SC goals such as excellence. Whereas process flow charts highlight task predecessors and successors, the Process Group Network view can identify more complex task relationships, and also highlight key and low value tasks, and orphan or bottle-neck PGs, and apply resourcing appropriately.

This paper focuses on different perspectives of ISCs when analyzed using network analysis. Valuable research may also focus on an understanding how PGs cluster in ISCs to suggest new topologies that may be useful for designing SCs focused on excellence rather than time criticality. This first step in investigating whether network analysis can provide additional valuable information to decision-makers indicates there is potential to take the approach further. A more in-depth collection of data on persons, resources managed and roles and their inter-relationships will provide more robust findings.

\section{REFERENCES}

[1] C.M. Harland, "Supply chain management: relationships, chains and networks”, British Journal of Management, vol. 7, pp. S63-S80, March 1996.

[2] S.C. Lazzarini, F.R. Chaddad and M.L. Cook, "Integrating supply chain and network analysis: the study of netchains", Journal of Chain and Network Science, vol. 1, no.1, pp.7-22, 2001.

[3] A. Nagurney, J. Dong and D. Zhang, “A supply chain network equilibrium model”, Transportation Research, vol. 38, pp. 281-303, 2002.

[4] B. Nooteboom, "Trust, opportunism and governance: A poscess and control model”, Organizational Studies, vol. 17, no. 6, pp. 985-1010, 1996.

[5] W.W. Powell, "Neither market nor hierarchy: network forms of organization”, Research in Organizational Behavior, vol. 12, pp. 295336, 1990.

[6] B.M. Beamon, "Supply chain design and analysis: Models and methods.", International Journal of Production Economics, vol. 55, pp. 281-294, 1998.

[7] F. Lin and M.J. Shaw, "Reenginerring the Order Fulfillment Process in Supply Chain Networks", International Journal of Flexible Manufacturing Systems, vol. 10, pp. 197-229, 1998.

[8] G. Stewart, "Supply Chain Performance Benchmarking Study Reveals Keys to Supply Chain Excellence”, Logistics Information Management, Vol. 8, No. 2, pp 38-44, 1995

[9] E. M. Goldratt, "What is this thing called theory of constraints and how should it be implemented?”, Croton-on-Hudson, N.Y., North River Press, 1990

[10] M. Christopher,"The Agile Supply Chain: Competing in Volatile Markets." Industrial Marketing Management, vol. 29, pp 37-44, 2000.

[11] A. Gunasekaran, C. Patel, et al. "A Framework for Supply Chain Performance Measurement." International Journal of Production Economics, vol. 87, pp 333-347, 2004.

[12] Supply Chain Council (SCC), Supply-Chain Operations Reference Model, Version 4.0., Pittsburgh, PA, 2000 Available http://supplychain.org/scor.

[13] S.A. Melnyk, E. W. Davis, et al., "Outcome-Driven Supply Chains." Sloan Management Review, Winter, pp 32-38, 2010.

[14] D.M. Lambert, T.L. Pohlen, "Supply Chain Metrics”, International Journal of Logistics Management, vol. 12, no. 1, pp 1-19, 2001.

[15] M. Christopher, "The Agile Supply Chain: Competing in Volatile Markets." Industrial Marketing Management, vol. 29, pp 37-44, 2000.

[16] O. Omta, H. Trienekens, et al. "Chain and network science: A research framework", Chain and Network Science, vol. 1, pp 1-6, 2001.

[17] D. Easley, J. Kleinberg, "Networks Crows and Markets: Reasoning about a highly connected world”, Cambridge University Press, Cambridge NY, 2010.

[18] S.P. Borgatti, X. Li, "Network Analysis in a Suply Chain Context", Journal of Supply chain Management, Spring, pp 1-17, 2009.

[19] T.G. Lewis, "Critical infrastructure Protection in Homeland Security", Wiley-Interscience, New Jersey, USA, 2006.

[20] M.E.J. Newman, “Networks: An Introduction”, Oxford University Press, Oxford, UK, 2010. 